\title{
Are Trans diagnostic models of eating disorders fit for purpose? A consideration of the evidence for food addiction
}

Short Title: Neuroadaptation and binge eating

Janet Treasure* ${ }_{1}$

Monica Leslie* $*_{1}$

Rayane Chami 1

Fernando Fernández-Aranda2

* Joint first author

1 Section of Eating Disorders, Department of Psychological Medicine, Institute of Psychiatry,

Psychology and Neuroscience, King's College London, London, UK

2 Eating Disorders Unit, Department of Psychiatry, University Hospital of Bellvitge and

CIBERobn (ISCIII), Barcelona, Spain

Corresponding Author:

Professor Janet Treasure

Section of Eating Disorders,

Department of Psychological Medicine

103 Denmark Hill, London, SE5 8AF, King’s College London

Email address: janet.treasure@kcl.ac.uk Telephone number: 004402078485972

Acknowledgements: The authors declare no conflict of interest. JT was supported by the National Institute for Health Research (NIHR) Mental Health Biomedical Research Centre at South London and Maudsley NHS Foundation Trust and King's College London. ML was supported by grants from the Swiss Fund for Anorexia Nervosa (Grant 43-14) and a King's Health Partners Challenge Fund (Grant R1405174). CIBEROBN is an initiative of ISCIII. 


\begin{abstract}
Explanatory models for eating disorders have changed over time to account for changing clinical presentations. The transdiagnostic model evolved from the maintenance model, which provided the framework for cognitive behavioural therapy for bulimia nervosa. However, for many individuals (especially those at the extreme ends of the weight spectrum), this account does not fully fit. New evidence generated from research framed within the food addiction hypothesis is synthesised here into a model that can explain recurrent binge eating behaviour. New interventions that target core maintenance elements identified within the model may be useful additions to a complex model of treatment for eating disorders.
\end{abstract}

Keywords: Bulimia nervosa, binge eating disorder, food addiction, neuroadaptation, insulin 


\section{Introduction}

Current treatments for bulimia nervosa and binge eating disorder are only moderately effective, with $30-50 \%$ of individuals achieving complete abstinence from binge eating at the end of treatment (Hay, 2013) and a 68\% remission rate at 9-year follow-up (Eddy et al., 2016). This suggests that the transdiagnostic model that underpins cognitive behavioural therapy may require modification in order to accommodate the diverse eating patterns and weight across the eating disorder spectrum. Eating behaviour has been relatively neglected (Treasure, Cardi, \& Kan, 2012) but the concept of food addiction has brought it into the foreground (Gearhardt, Boswell, \& White, 2014; Gearhardt et al., 2012; Granero et al., 2014; Meule \& Gearhardt, 2014; Schulte \& Gearhardt, 2017). Nonetheless, the concept of food addiction is controversial (Finlayson, 2017; Hebebrand et al., 2014; Long, Blundell, \& Finlayson, 2015; Schulte, Potenza, \& Gearhardt, 2017), in part due to the different levels of description being used. For example, the Yale Food Addiction Scale (Gearhardt, Corbin, \& Brownell, 2009) examines behaviours and subjective reports, while the focus of other studies has been on underpinning mechanisms (Colantuoni et al., 2002; Colantuoni et al., 2001). Some of the controversy may stem from semantics: does addiction imply a set of behaviours, or a form of neuroadaptation within hedonic circuits, or an underlying disease process (Lewis, 2017)? If we step aside from the linguistic term "addiction", with all the stigma and social implications it may carry, and instead focus on the function that related processes serve, this conceptualisation may prove a useful frame for work within the field. Targeting the maintenance factors underpinned by addiction-related neural processes may enhance our ability to prevent and treat these disorders, which lead to misery and disability in many domains (Gramaglia, Brytek-Matera, Rogoza, \& Zeppegno, 2017; Simpson \& Mazzeo, 2017). In the following account, we suggest an update to the model of binge eating disorder and bulimia nervosa, which incorporates some of the new 
evidence that is emerging. First we consider the profound changes in the epidemiology of eating disorders over the last 50 years.

\section{Epidemiology}

An increasing number of people received a diagnosis for bulimia nervosa in the UK in the eighties (Currin, Schmidt, Treasure, \& Jick, 2005; Turnbull, Ward, Treasure, Jick, \& Derby, 1996) and binge eating disorder in the new millennium (Micali, Hagberg, Petersen, \& Treasure, 2013). Possible new forms of eating disorders such as orthorexia nervosa (Gramaglia et al., 2017; Simpson \& Mazzeo, 2017) and diabulimia (Wilson, 2012) have been described more recently. This increase in eating disorders parallels the worldwide increase in the prevalence of obesity (Ng et al., 2014). There are several explanations for this rapid increase in eating and weight problems, including changes to the food environment and associated novel interactions with individual vulnerabilities.

In the West, in particular, the evolving food environment has changed what and how we eat (Lewis, 2017). Foods have been modified to become more accessible, cheap, and palatable, while nutrients have been ultra-processed and /or purified (Gramaglia et al., 2017). Food now requires little effort to procure and prepare, and is therefore less bound within social processes. At the same time, the relevance of food and eating to health and body image has become a dominant discourse. Fatness is stigmatised (de la Haye, Dijkstra, Lubbers, van Rijsewijk, \& Stolk, 2017; Di Pasquale \& Celsi, 2017), "fat talk" is associated with body dissatisfaction (Mills \& Fuller-Tyszkiewicz, 2017) and abnormal eating practices (Arroyo, Segrin, Harwood, \& Bonito, 2017), while thinness and muscularity are valued as the ideal body form (Karazsia, Murnen, \& Tylka, 2017). What is the evidence that these changes in the food environment could lead to changes in eating behaviours? 


\section{Proof of Concept Animal Models: Changes in the Food environment as Risk Factors for Binge Eating Disorder}

Animal studies have demonstrated proof of the concept that manipulations of the food environment can produce "binge eating". Putative risk factors including a period of undernutrition, followed by the intermittent addition of palatable food (high sugar and fat combinations) and stress (particularly social stress), have been shown to lead to "binge eating" (Murray, Tulloch, Chen, \& Avena, 2015; Razzoli, Pearson, Crow, \& Bartolomucci, 2017; Wiss, Criscitelli, Gold, \& Avena, 2017). Interestingly, animals exposed to this food schedule exhibit signs of food addiction, such as physical withdrawal symptoms, when intermittent palatable sucrose intake is followed by administration of an opioid antagonist (Colantuoni et al., 2002). These animals are also more vulnerable to developing other addictive behaviours (Avena, 2010; Avena \& Bocarsly, 2012; Avena, Bocarsly, \& Hoebel, 2012). Moreover, deeper examination of the hedonic circuits involved has shown neuroadaptive changes in dopamine and opiate neurons (Avena, Rada, \& Hoebel, 2009; Rada, Avena, \& Hoebel, 2005). This is of interest as the mechanisms underpinning substance abuse are also thought to involve "hijacking" of normal hedonic processes (Lewis, 2017).

One theory of addiction processes is that aspects of the pharmacology (more potent agents) or the pharmacokinetics (e.g. rapid rate of change in levels of a psychoactive chemical) leads to greater activation and sensitisation in "wanting" component of the hedonic system (Volkow, Fowler, Wang, \& Swanson, 2004). In turn, this leads to secondary neuroadaptive changes (Sweatt, 2016), including the down-regulation of dopamine and opioid receptors. As tolerance develops along with persistent and increasing craving for the substance, individuals engage in particular behaviours to restore hedonic balance. "Addictive behaviours" are considered out of control and shameful activities, and are therefore often carried out in solitude. The repeated occurrence of these behaviours therefore results in a shift in the overall balance between 
positive and negative affect, thereby increasing the desire for further activation of the hedonic system (Lewis, 2017; Probst \& van Eimeren, 2013). This can lead to the development of a vicious circle of behaviour, where susceptibility is potentially moderated by gender (JiménezMurcia et al., 2017).

\section{The Concept of Food Addiction}

It follows from this model that certain foods may have an addictive potential because of a similar change in the "pharmacokinetics" of glucose and possibly fat metabolism. For example, foods with a high glycaemic load have the potential to cause greater fluxes in blood glucose. A survey examining the addictive potential of different foods found technologically-processed foods with added refined carbohydrate and fat, and /or with a higher glycaemic load were most implicated (Schulte, Avena, \& Gearhardt, 2015). Support for this concept comes from an experimental study in men which found that foods with a high glycaemic load led to greater post meal changes in hunger and activation of reward circuits (Lennerz et al., 2013). Previous evidence has demonstrated individual variation in susceptibility to this effect (Zeevi et al., 2015). For example, insulin resistance or insulin omission (a key behaviour in "diabulimia") might enhance an individual's potential to develop a cycle of addictive food consumption because of the wider swings in blood sugar. The same explanation may explain the similar effects of self-induced vomiting. These physiological processes may account for the higher risk of developing an eating disorder in type 1 diabetes (Young et al., 2013), and may also explain the fact that higher levels of binge-purge behaviours in eating disorders worsen prognosis and increase treatment drop-out (Custal et al., 2014; Vall \& Wade, 2015).

\section{What is the evidence for similarity in brain circuits between binge eating disorder and} substance abuse disorders? 
Recurrent binge eating of foods high in fat and sugar has been associated with desensitisation of opioid and dopamine receptors (Colantuoni et al., 2002; Colantuoni et al., 2001). This pattern mimics the neural underpinning of tolerance and dependence observed in substance use disorders (Christie, 2008). Indeed, Broft and colleagues have similarly reported a lower level of dopamine binding in the striatal region for individuals with bulimia nervosa (Broft et al., 2012). Furthermore, they found that lower levels of dopamine binding were correlated with greater severity of bulimic symptoms (Broft et al., 2012).

It is also notable that common neural substrates appear to be relevant in supporting both substance disorders and binge-type eating disorders (Berridge, 2009; Kessler, Hutson, Herman, \& Potenza, 2016; Mameli et al., 2009). The ventral tegmental area and nucleus accumbens play important roles in the processing of reward and maintenance of addictions (Berridge, 2009) Specifically, it has been shown that cocaine use results in the initial potentiation of synapses within the ventral tegmental area (Mameli et al., 2009), which gradually comes to lead to neuroplastic changes within the dorsal striatum (Everitt \& Robbins, 2013) (in a path acting via the nucleus accumbens) (Mameli et al., 2009). These changes in the dorsal striatum subsequently consolidate the compulsive nature of the addiction over time. The ventral tegmental area and nucleus accumbens are also highly involved in the processing of taste reward (Berridge, 2009) and, as cited above, reduced dopamine binding in the these same regions of the striatum have been noted in bulimia nervosa (Broft et al., 2012; Steward, Menchón, Jiménez-Murcia, Soriano-Mas, \& Fernández-Aranda, 2017) as well as obesity (Wang, Volkow, Thanos, \& Fowler, 2004) (as is also seen in individuals with drug addictions) (Wang et al., 2004).

Corresponding with these findings, Gearhardt and colleagues have previously investigated individuals high in food addiction and found that the pattern of neural activation in response to 
food cues bears similarity to that observed in individuals with substance disorders in response to drug cues (Gearhardt et al., 2011).

It is interesting to note that these similarities in neural circuits underpinning reward processing are also accompanied by similarities in general neuropsychological traits. Voon used a paradigm that measured aspects of risk taking (valence, probability, and value) and found similarities between people with binge eating disorders and substance abuse favoured greater risk taking than healthy controls when anticipating rewards (Voon, Morris, et al., 2015). In the loss domain, however, there were some differences, indicating that individuals with binge eating disorder may not be quite as prone to risk taking when faced with a high probability of loss. Similar findings were obtained when obesity, substance-related disorders and behavioural addictions were compared on decision making tasks (Mallorquí-Bagué et al., 2016).

It has been argued that binge eating disorder and addiction are two clusters of one disorder, with impulsivity and compulsivity as transdiagnostic traits (Figee et al., 2016; Jiménez-Murcia et al., 2015; Kessler et al., 2016). Compulsive patterns of behaviour, generally, are believed to be underpinned by anomalies in circuits relating to reward and punishment (particularly among striato-thalamo-cortical circuits (Volkow \& Fowler, 2000)) .

\section{Building Models for Understanding Bulimia Nervosa and Binge Eating disorder}

Fairburn developed a maintenance model for bulimia nervosa in 1981, forming the basis of cognitive behavioural treatment (CBT) (Fairburn, 1981) This was later adapted into the transdiagnostic model, designed to apply to all forms of eating disorder (Fairburn, Cooper, \& Shafran, 2003). In these earlier models, the biology and behaviour related to eating and appetite had been largely ignored (Treasure et al., 2012). However, a simple transdiagnostic formulation cannot easily account for the divergent pattern of eating behaviour and weight between restrictive anorexia nervosa and binge eating disorder. Explanatory models for restrictive 
anorexia nervosa (AN) (low appetite, aversion to satiety) and both bulimia nervosa (BN) and binge eating disorder (BED) (high appetite, weak satiation) need to account for these differences in the domain of appetitive traits.

The behavioural susceptibility theory has gone some way toward addressing differences between restrictive $\mathrm{AN}$ and $\mathrm{BN} / \mathrm{BED}$, as it suggests that eating behaviours lie on a continuum (Carnell \& Wardle, 2008; Llewellyn \& Fildes, 2017). The behavioural susceptibility theory was built upon evidence from precision phenotyping of appetite in large longitudinal studies (Carnell \& Wardle, 2008; Llewellyn \& Fildes, 2017; Llewellyn \& Wardle, 2015). These studies have shown that the variation in appetite is measurable from birth, is highly heritable, and that 'food-approach' traits (greater appetite for food) predispose individuals to obesity (Llewellyn \& Fildes, 2017). Conversely, 'food-avoidance' traits, including poorer appetite and a stronger predisposition to satiety, predispose individuals to being underweight (Llewellyn \& Fildes, 2017).

It is possible that this dissimilarity relates to variants of the FTO gene, which has been associated with AN, BN and binge eating (Micali, Field, Treasure, \& Evans, 2015; Muller et al., 2012) . This hypothesis is supported by genome-wide association studies and case-control studies indicating that single nucleotide polymorphisms in the FTO gene (including at rs9930506 and rs9939609) are associating with increased body mass index (BMI) in both European American, Hispanic American, British, and Japanese populations (Frayling et al., 2007; Hotta et al., 2008; Scuteri et al., 2007). Furthermore, lab studies have indicated that the A allele at rs9939609 within the FTO gene is associated with significantly greater food intake in test meals (Cecil, Tavendale, Watt, Hetherington, \& Palmer, 2008; Wardle, Llewellyn, Sanderson, \& Plomin, 2009). Thus there may be biological factors that predispose to the various forms of eating disorders, with the greatest contrasts between binge eating disorders and restricting anorexia nervosa. 
New findings from genetic studies suggest that both psychological and somatic aspects may need to feature in our models of eating disorders (Duncan et al., 2017). One example of this is the disordered eating food addiction nutrition guide (DEFANG) (Wiss \& Brewerton, 2016), which uses two dimensions, weight and predisposition, as a means of categorising the different forms of eating disorders.

We have developed a maintenance model for binge eating disorder and bulimia nervosa (Figure 1), which translates findings from animal studies and builds upon evidence for the theories described above. This differs from the earlier models by including differences in appetitive traits (i.e., the balance between reward and punishment sensitivity) and aspects of executive function (such as impulsivity), while also considering neuroadaptive changes. The five primary maintenance factors proposed within this model are as follows:

(1) The salience of food reward is increased as a result of a predisposing susceptibility. This susceptibility to food addiction reaches the full phenotype following strict dieting behaviour, which further increases the incentive salience of food cues (Berridge \& Robinson, 1998). (2) The likelihood of food addiction is further increased within the context of chronic stress and problems with interpersonal relationships, which result in a paucity of other sources of reward. (3) The Western food environment fosters the intermittent consumption of palatable foods with a high glycaemic index in large quantities. Traits of impulsivity and difficulties in delaying action towards rewards can exaggerate susceptibilities to these triggers. (4) Processed foods with added fat and refined carbohydrates produce wide fluxes in blood glucose. These swings in blood sugar can be accentuated by purging behaviours and a lack of, or resistance to, the effects of insulin. (5) In turn, these gradients in blood glucose alter the pattern of dopamine firing (Lennerz et al., 2013). It is thought that these changes in dopamine activity lead to neuroadaptation and the formation of a habitual pattern of behaviour, whereby the drive to eat is no longer dependent on the goal to reduce hunger and is rather triggered by food cues in the 
environment. Eating behaviour becomes compulsive (Robbins, Gillan, Smith, de Wit, \& Ersche, 2012; Voon, Derbyshire, et al., 2015) and a vicious circle is set in motion. This model can be used as a framework for treatment (Figure 1).

\section{Implications for Treatment}

This updated model for binge eating suggests there is potential for adaptations to the traditional treatment approaches. Specifically, we identify five potential maintaining mechanisms within the updated model that provide potential targets for treatment within the domains of psychotherapy and nutrition guidance (presented in Figure 2). These treatment targets are as follows:

- Target 1: An important maintenance factor within the model is the large amount of glucose flux induced by the intermittent consumption of foods with a high glycaemic index. A major difference in the updated model would be the recommendation to avoid and abstain from technologically-modified foods that trigger over-eating, or to manage them in a way that reduces harm (Wiss \& Brewerton, 2016) rather than encouraging an absolute "no dieting approach".

- Target 2: Another mechanism that promotes the maladaptive neuroadaptation is the limitation and restriction of all forms of food. While individuals would be recommended to avoid highly-processed foods, treatment based on this new model would continue to discourage individuals from restricting healthy foods, to prevent them from reaching a state of semi-starvation.

- Target 3: In order to counteract habit formation that entrenches stimulus-responses association between food cues and eating, another addition may be to add treatments, which target impulsivity and habitual patterns of responding. Pilot studies for computerised approaches such as stop signal and go/no-go training have potential 
(Adams, Lawrence, Verbruggen, \& Chambers, 2017; Lawrence, Verbruggen, Morrison, Adams, \& Chambers, 2015; Preuss, Pinnow, Schnicker, \& Legenbauer, 2017; Schag, Schönleber, Teufel, Zipfel, \& Giel, 2013; Turton, Bruidegom, Cardi, Hirsch, \& Treasure, 2016) , but also virtual reality cue exposure (Ferrer-García et al., 2017) and emotional regulation video game training (Fernandez-Aranda et al., 2015) and modification to make these training programmes accessible, more rewarding, and personalised are in progress (Forman et al., 2017). The updated model also opens up the possibility for new pharmacological treatments targeting the sensitisation to food cues, while preventing receptor tolerance triggered by binge eating. For example, Lisdexamphetamine, which targets dopamine systems in binge eating disorder, is already available in the US (Agh, Pawaskar, Nagy, Lachaine, \& Voko, 2016; McElroy et al., 2016). Work is in progress to further examine drugs which act on the opiate system (Cambridge et al., 2013) and the impact of oxytocin (Kim, Eom, Yang, Kang, \& Treasure, 2015; Leppanen et al., 2017) (which is known to interact with the opiate system) (Flanagan, Verbalis, \& Stricker, 1988).

- Target 4: Binge eating is partially maintained, following a negative reinforcement model, by high levels of stress and reward seeking that is not satisfied in other domains of life. The model therefore highlights the importance of developing positive anxiety managements and coping mechanisms. It is also beneficial to support positive social connections and identify sources of meaning in other areas of life.

- Target 5: Maladaptive compensatory behaviours such as vomiting and insulin omission further contribute to the large swings in blood glucose that maintain the disorder. Psychoeducation and supporting the development of coping mechanisms to deter these behaviours is therefore also recommended.

\section{Suggestions for Future Research}


While the body of evidence described above currently provides a sound basis for this updated model of binge eating behaviour, our understanding of and ability to effectively treat bulimia nervosa and binge eating disorder would benefit from further research in a number of areas. These suggestions are summarised in Table 1.

We recommend future research continue to refine our understanding of the 'food approach' phenotype. Future work specifically identifying the profiles of traits that are most closely linked to the development of recurring binge eating behaviour would be particularly beneficial in elaborating upon the currently proposed model, in order to further clarify links between traits, environmental cues, thoughts, and disordered eating behaviour. Clarifying which food avoidance traits are most relevant to the onset and maintenance of anorexia nervosa would be similarly useful for the field.

Based on the recognition of neural similarities between substance addiction and binge eating in the proposed model, we would further encourage future research to draw inspiration from interventions previously developed within the addiction sciences and investigate their relevance and effectiveness for curbing binge eating behaviour.

Finally, further research into pharmacological and hormonal treatments that prevent the sensitisation to binge cues and/or reduce receptor tolerance to the 'liking' of food stimuli is warranted based on the current model. Relevant research into the potential therapeutic effects of oxytocin and opioid antagonists for binge eating is currently underway; however, research into pharmacological treatments for eating disorders is still nascent and would benefit from further investigation.

\section{Conclusion}

We have argued from the impressive evidence from clinical and preclinical science that it is time to put eating behaviour into a central place in models of eating disorders. Changes in the 
food environment interacting with individual vulnerability are recognised to be key predisposing risk factors. However, neuroadaptive changes in reward circuits are thought to maintain these disorders. The next step is to develop the evidence for interventions targeting these risk and maintenance factors, with the hope of reversing the increasing prevalence of these problems. 


\section{References:}

Adams, R. C., Lawrence, N. S., Verbruggen, F., \& Chambers, C. D. (2017). Training response inhibition to reduce food consumption: Mechanisms, stimulus specificity and appropriate training protocols. Appetite, 109, 11-23. doi:10.1016/j.appet.2016.11.014

Agh, T., Pawaskar, M., Nagy, B., Lachaine, J., \& Voko, Z. (2016). The Cost Effectiveness of Lisdexamfetamine Dimesylate for the Treatment of Binge Eating Disorder in the USA. Clin Drug Investig, 36(4), 305-312. doi:10.1007/s40261-016-0381-3

Arroyo, A., Segrin, C., Harwood, J., \& Bonito, J. A. (2017). Co-rumination of fat talk and weight control practices: An application of confirmation theory. Health communication, 32(4), 438-450.

Avena, N. M. (2010). The study of food addiction using animal models of binge eating. Appetite, 55(3), 734-737. doi:10.1016/j.appet.2010.09.010

Avena, N. M., \& Bocarsly, M. E. (2012). Dysregulation of brain reward systems in eating disorders: neurochemical information from animal models of binge eating, bulimia nervosa, and anorexia nervosa. Neuropharmacology, 63(1), 87-96. doi:10.1016/j.neuropharm.2011.11.010

Avena, N. M., Bocarsly, M. E., \& Hoebel, B. G. (2012). Animal models of sugar and fat bingeing: relationship to food addiction and increased body weight. Methods $\mathrm{Mol}$ Biol, 829, 351-365. doi:10.1007/978-1-61779-458-2_23

Avena, N. M., Rada, P., \& Hoebel, B. G. (2009). Sugar and fat bingeing have notable differences in addictive-like behavior. $J$ Nutr, 139(3), 623-628. doi:10.3945/jn.108.097584

Berridge, K. C. (2009). 'Liking'and 'wanting'food rewards: brain substrates and roles in eating disorders. Physiology \& behavior, 97(5), 537-550. 
Berridge, K. C., \& Robinson, T. E. (1998). What is the role of dopamine in reward: hedonic impact, reward learning, or incentive salience? Brain Res Rev, 28(3), 309-369.

Broft, A., Shingleton, R., Kaufman, J., Liu, F., Kumar, D., Slifstein, M., . . A Attia, E. (2012). Striatal dopamine in bulimia nervosa: a PET imaging study. International Journal of Eating Disorders, 45(5), 648-656.

Cambridge, V. C., Ziauddeen, H., Nathan, P. J., Subramaniam, N., Dodds, C., Chamberlain, S. R., . . Fletcher, P. C. (2013). Neural and behavioral effects of a novel mu opioid receptor antagonist in binge-eating obese people. Biol Psychiatry, 73(9), 887-894. doi:10.1016/j.biopsych.2012.10.022

Carnell, S., \& Wardle, J. (2008). Appetite and adiposity in children: evidence for a behavioral susceptibility theory of obesity. Am J Clin Nutr, 88(1), 22-29.

Cecil, J. E., Tavendale, R., Watt, P., Hetherington, M. M., \& Palmer, C. N. (2008). An obesity-associated FTO gene variant and increased energy intake in children. New England Journal of Medicine, 359(24), 2558-2566.

Christie, M. (2008). Cellular neuroadaptations to chronic opioids: tolerance, withdrawal and addiction. British journal of pharmacology, 154(2), 384-396.

Colantuoni, C., Rada, P., McCarthy, J., Patten, C., Avena, N. M., Chadeayne, A., \& Hoebel, B. G. (2002). Evidence that intermittent, excessive sugar intake causes endogenous opioid dependence. Obesity, 10(6), 478-488.

Colantuoni, C., Schwenker, J., McCarthy, J., Rada, P., Ladenheim, B., Cadet, J.-L., . . . Hoebel, B. (2001). Excessive sugar intake alters binding to dopamine and mu-opioid receptors in the brain. Neuroreport, 12(16), 3549-3552.

Currin, L., Schmidt, U., Treasure, J., \& Jick, H. (2005). Time trends in eating disorder incidence. Br J Psychiatry, 186, 132-135. doi:10.1192/bjp.186.2.132 
Custal, N., Arcelus, J., Agüera, Z., Bove, F. I., Wales, J., Granero, R., . . Alonso, P. (2014). Treatment outcome of patients with comorbid type 1 diabetes and eating disorders. BMC psychiatry, 14(1), 140.

de la Haye, K., Dijkstra, J. K., Lubbers, M. J., van Rijsewijk, L., \& Stolk, R. (2017). The dual role of friendship and antipathy relations in the marginalization of overweight children in their peer networks: The TRAILS Study. PLoS One, 12(6), e0178130. doi:10.1371/journal.pone.0178130

Di Pasquale, R., \& Celsi, L. (2017). Stigmatization of Overweight and Obese Peers among Children. Front Psychol, 8, 524. doi:10.3389/fpsyg.2017.00524

Duncan, L., Yilmaz, Z., Gaspar, H., Walters, R., Goldstein, J., Anttila, V., . . Bulik, C. M. (2017). Significant Locus and Metabolic Genetic Correlations Revealed in GenomeWide Association Study of Anorexia Nervosa. Am J Psychiatry, appiajp201716121402. doi:10.1176/appi.ajp.2017.16121402

Eddy, K. T., Tabri, N., Thomas, J. J., Murray, H. B., Keshaviah, A., Hastings, E., . . Franko, D. L. (2016). Recovery From Anorexia Nervosa and Bulimia Nervosa at 22-Year Follow-Up. J Clin Psychiatry. doi:10.4088/JCP.15m10393

Everitt, B. J., \& Robbins, T. W. (2013). From the ventral to the dorsal striatum: devolving views of their roles in drug addiction. Neuroscience \& Biobehavioral Reviews, 37(9), 1946-1954.

Fairburn, C. (1981). A cognitive behavioural approach to the treatment of bulimia. Psychological medicine, 11(4), 707-711.

Fairburn, C., Cooper, Z., \& Shafran, R. (2003). Cognitive behaviour therapy for eating disorders: A "transdiagnostic" theory and treatment. Behaviour research and therapy, 41(5), 509-528. 
Fernandez-Aranda, F., Jimenez-Murcia, S., Santamaría, J. J., Giner-Bartolomé, C., Mestre-Bach, G., Granero, R., . . Magnenat-Thalmann, N. (2015). The use of videogames as complementary therapeutic tool for cognitive behavioral therapy in bulimia nervosa patients. Cyberpsychology, Behavior, and Social Networking, 18(12), 744-751.

Ferrer-García, M., Gutiérrez-Maldonado, J., Pla-Sanjuanelo, J., Vilalta-Abella, F., Riva, G., Clerici, M., . . Forcano, L. (2017). A Randomised Controlled Comparison of Second-Level Treatment Approaches for Treatment-Resistant Adults with Bulimia Nervosa and Binge Eating Disorder: Assessing the Benefits of Virtual Reality Cue Exposure Therapy. European Eating Disorders Review.

Figee, M., Pattij, T., Willuhn, I., Luigjes, J., van den Brink, W., Goudriaan, A., . . Denys, D. (2016). Compulsivity in obsessive-compulsive disorder and addictions. Eur Neuropsychopharmacol, 26(5), 856-868. doi:10.1016/j.euroneuro.2015.12.003

Finlayson, G. (2017). Food addiction and obesity: unnecessary medicalization of hedonic overeating. Nat Rev Endocrinol, 13(8), 493-498. doi:10.1038/nrendo.2017.61

Flanagan, L. M., Verbalis, J. G., \& Stricker, E. M. (1988). Naloxone potentiation of effects of cholecystokinin and lithium chloride on oxytocin secretion, gastric motility and feeding. Neuroendocrinology, 48(6), 668-673.

Forman, E. M., Goldstein, S. P., Flack, D., Evans, B. C., Manasse, S. M., \& Dochat, C. (2017). Promising technological innovations in cognitive training to treat eatingrelated behavior. Appetite. doi:10.1016/j.appet.2017.04.011

Frayling, T. M., Timpson, N. J., Weedon, M. N., Zeggini, E., Freathy, R. M., Lindgren, C. M., . . Rayner, N. W. (2007). A common variant in the FTO gene is associated with body mass index and predisposes to childhood and adult obesity. Science, 316(5826), 889-894. 
Gearhardt, A. N., Boswell, R. G., \& White, M. A. (2014). The association of "food addiction" with disordered eating and body mass index. Eat Behav, 15(3), 427-433. doi:10.1016/j.eatbeh.2014.05.001

Gearhardt, A. N., Corbin, W. R., \& Brownell, K. D. (2009). Preliminary validation of the Yale food addiction scale. Appetite, 52(2), 430-436.

Gearhardt, A. N., White, M. A., Masheb, R. M., Morgan, P. T., Crosby, R. D., \& Grilo, C. M. (2012). An examination of the food addiction construct in obese patients with binge eating disorder. Int J Eat Disord, 45(5), 657-663. doi:10.1002/eat.20957

Gearhardt, A. N., Yokum, S., Orr, P. T., Stice, E., Corbin, W. R., \& Brownell, K. D. (2011). Neural correlates of food addiction. Archives of general psychiatry, 68(8), 808-816.

Gramaglia, C., Brytek-Matera, A., Rogoza, R., \& Zeppegno, P. (2017). Orthorexia and anorexia nervosa: two distinct phenomena? A cross-cultural comparison of orthorexic behaviours in clinical and non-clinical samples. BMC Psychiatry, 17(1), 75. doi:10.1186/s12888-017-1241-2

Granero, R., Hilker, I., Aguera, Z., Jimenez-Murcia, S., Sauchelli, S., Islam, M. A., . . Fernandez-Aranda, F. (2014). Food addiction in a Spanish sample of eating disorders: DSM-5 diagnostic subtype differentiation and validation data. Eur Eat Disord Rev, 22(6), 389-396. doi:10.1002/erv.2311

Hay, P. (2013). A systematic review of evidence for psychological treatments in eating disorders: 2005-2012. Int J Eat Disord, 46(5), 462-469. doi:10.1002/eat.22103

Hebebrand, J., Albayrak, Ö., Adan, R., Antel, J., Dieguez, C., de Jong, J., . . Murphy, M. (2014). "Eating addiction", rather than "food addiction", better captures addictive-like eating behavior. Neuroscience \& Biobehavioral Reviews, 47, 295306. 
Hotta, K., Nakata, Y., Matsuo, T., Kamohara, S., Kotani, K., Komatsu, R., . . Masuzaki, H. (2008). Variations in the FTO gene are associated with severe obesity in the Japanese. Journal of human genetics, 53(6), 546-553.

Jiménez-Murcia, S., Granero, R., Wolz, I., Baño, M., Mestre-Bach, G., Steward, T., . . . Casanueva, F. F. (2017). Food Addiction in Gambling Disorder: Frequency and Clinical Outcomes. Front Psychol, 8.

Jiménez-Murcia, S., Granero, R., Moragas, L., Steiger, H., Israel, M., Aymamí, N., . . . Sánchez, I. (2015). Differences and similarities between bulimia nervosa, compulsive buying and gambling disorder. European Eating Disorders Review, 23(2), $111-118$.

Karazsia, B. T., Murnen, S. K., \& Tylka, T. L. (2017). Is body dissatisfaction changing across time? A cross-temporal meta-analysis. Psychol Bull, 143(3), 293-320. doi:10.1037/bul0000081

Kessler, R. M., Hutson, P. H., Herman, B. K., \& Potenza, M. N. (2016). The neurobiological basis of binge-eating disorder. Neuroscience \& Biobehavioral Reviews, 63, 223-238.

Kim, Y. R., Eom, J. S., Yang, J. W., Kang, J., \& Treasure, J. (2015). The Impact of Oxytocin on Food Intake and Emotion Recognition in Patients with Eating Disorders: A Double Blind Single Dose Within-Subject Cross-Over Design. PLoS One, 10(9), e0137514. doi:10.1371/journal.pone.0137514

Lawrence, N. S., Verbruggen, F., Morrison, S., Adams, R. C., \& Chambers, C. D. (2015). Stopping to food can reduce intake. Effects of stimulus-specificity and individual differences in dietary restraint. Appetite, 85, 91-103. doi:10.1016/j.appet.2014.11.006

Lennerz, B. S., Alsop, D. C., Holsen, L. M., Stern, E., Rojas, R., Ebbeling, C. B., . . Ludwig, D. S. (2013). Effects of dietary glycemic index on brain regions related to reward and craving in men. Am J Clin Nutr, 98(3), 641-647. doi:10.3945/ajcn.113.064113 
Leppanen, J., Cardi, V., Ng, K. W., Paloyelis, Y., Stein, D., Tchanturia, K., \& Treasure, J. (2017). The effects of intranasal oxytocin on smoothie intake, cortisol and attentional bias in anorexia nervosa. Psychoneuroendocrinology, 79, 167-174. doi:10.1016/j.psyneuen.2017.01.017

Lewis, M. (2017). Addiction and the Brain: Development, Not Disease. Neuroethics, 10(1), 7-18. doi:10.1007/s12152-016-9293-4

Llewellyn, C., \& Fildes, A. (2017). Behavioural Susceptibility Theory: Professor Jane Wardle and the Role of Appetite in Genetic Risk of Obesity. Current Obesity Reports, $6(1), 38-45$.

Llewellyn, C., \& Wardle, J. (2015). Behavioral susceptibility to obesity: gene-environment interplay in the development of weight. Physiology \& behavior, 152, 494-501.

Long, C. G., Blundell, J. E., \& Finlayson, G. (2015). A Systematic Review of the Application And Correlates of YFAS-Diagnosed 'Food Addiction' in Humans: Are Eating-Related 'Addictions' a Cause for Concern or Empty Concepts? Obes Facts, 8(6), 386-401. doi:10.1159/000442403

Mallorquí-Bagué, N., Fagundo, A. B., Jimenez-Murcia, S., De la Torre, R., Baños, R. M., Botella, C., . . F Fernández-Real, J. M. (2016). Decision Making Impairment: A Shared Vulnerability in Obesity, Gambling Disorder and Substance Use Disorders? PloS one, 11(9), e0163901.

Mameli, M., Halbout, B., Creton, C., Engblom, D., Parkitna, J. R., Spanagel, R., \& Lüscher, C. (2009). Cocaine-evoked synaptic plasticity: persistence in the VTA triggers adaptations in the NAc. Nature neuroscience, 12(8), 1036-1041.

McElroy, S. L., Mitchell, J. E., Wilfley, D., Gasior, M., Ferreira-Cornwell, M. C., McKay, M., . . Hudson, J. I. (2016). Lisdexamfetamine dimesylate effects on binge 
eating behaviour and obsessive-compulsive and impulsive features in adults with binge eating disorder. European Eating Disorders Review, 24(3), 223-231.

Meule, A., \& Gearhardt, A. N. (2014). Food addiction in the light of DSM-5. Nutrients, 6(9), 3653-3671. doi:10.3390/nu6093653

Micali, N., Field, A. E., Treasure, J. L., \& Evans, D. M. (2015). Are obesity risk genes associated with binge eating in adolescence? Obesity (Silver Spring), 23(8), 17291736. doi:10.1002/oby. 21147

Micali, N., Hagberg, K. W., Petersen, I., \& Treasure, J. L. (2013). The incidence of eating disorders in the UK in 2000-2009: findings from the General Practice Research Database. BMJ Open, 3(5). doi:10.1136/bmjopen-2013-002646

Mills, J., \& Fuller-Tyszkiewicz, M. (2017). Fat Talk and Body Image Disturbance: A Systematic Review and Meta-Analysis. Psychology of Women Quarterly, 41(1), 114129.

Muller, T. D., Greene, B. H., Bellodi, L., Cavallini, M. C., Cellini, E., Di Bella, D., . . Hinney, A. (2012). Fat mass and obesity-associated gene (FTO) in eating disorders: evidence for association of the rs 9939609 obesity risk allele with bulimia nervosa and anorexia nervosa. Obes Facts, 5(3), 408-419. doi:10.1159/000340057

Murray, S. M., Tulloch, A. J., Chen, E. Y., \& Avena, N. M. (2015). Insights revealed by rodent models of sugar binge eating. CNS Spectr, 20(6), 530-536. doi:10.1017/S1092852915000656

Ng, M., Fleming, T., Robinson, M., Thomson, B., Graetz, N., Margono, C., . . Gakidou, E. (2014). Global, regional, and national prevalence of overweight and obesity in children and adults during 1980-2013: a systematic analysis for the Global Burden of Disease Study 2013. Lancet, 384(9945), 766-781. doi:10.1016/S01406736(14)60460-8 
Preuss, H., Pinnow, M., Schnicker, K., \& Legenbauer, T. (2017). Improving Inhibitory Control Abilities (ImpulsE)-A Promising Approach to Treat Impulsive Eating? Eur Eat Disord Rev. doi:10.1002/erv.2544

Probst, C. C., \& van Eimeren, T. (2013). The functional anatomy of impulse control disorders. Current neurology and neuroscience reports, 13(10), 386.

Rada, P., Avena, N. M., \& Hoebel, B. G. (2005). Daily bingeing on sugar repeatedly releases dopamine in the accumbens shell. Neuroscience, 134(3), 737-744. doi:10.1016/j.neuroscience.2005.04.043

Razzoli, M., Pearson, C., Crow, S., \& Bartolomucci, A. (2017). Stress, overeating, and obesity: Insights from human studies and preclinical models. Neurosci Biobehav Rev, 76(Pt A), 154-162. doi:10.1016/j.neubiorev.2017.01.026

Robbins, T. W., Gillan, C. M., Smith, D. G., de Wit, S., \& Ersche, K. D. (2012). Neurocognitive endophenotypes of impulsivity and compulsivity: towards dimensional psychiatry. Trends Cogn Sci, 16(1), 81-91. doi:10.1016/j.tics.2011.11.009

Schag, K., Schönleber, J., Teufel, M., Zipfel, S., \& Giel, K. (2013). Food-related impulsivity in obesity and Binge Eating Disorder-a systematic review. Obesity reviews, 14(6), 477-495.

Schulte, E. M., Avena, N. M., \& Gearhardt, A. N. (2015). Which foods may be addictive? The roles of processing, fat content, and glycemic load. PloS one, 10(2), e0117959.

Schulte, E. M., \& Gearhardt, A. N. (2017). Development of the Modified Yale Food Addiction Scale Version 2.0. European Eating Disorders Review, 25(4), 302-308.

Schulte, E. M., Potenza, M. N., \& Gearhardt, A. N. (2017). A commentary on the "eating addiction" versus "food addiction" perspectives on addictive-like food consumption. Appetite, 115, 9-15. 
Scuteri, A., Sanna, S., Chen, W.-M., Uda, M., Albai, G., Strait, J., . . Usala, G. (2007). Genome-wide association scan shows genetic variants in the FTO gene are associated with obesity-related traits. PLoS Genetics, 3(7), e115.

Simpson, C. C., \& Mazzeo, S. E. (2017). Attitudes toward orthorexia nervosa relative to DSM-5 eating disorders. Int J Eat Disord. doi:10.1002/eat.22710

Steward, T., Menchón, J., Jiménez-Murcia, S., Soriano-Mas, C., \& Fernández-Aranda, F. (2017). Neural network alterations across eating disorders: a narrative review of fMRI studies. Current neuropharmacology.

Sweatt, J. D. (2016). Neural plasticity and behavior - sixty years of conceptual advances. $J$ Neurochem, 139 Suppl 2, 179-199. doi:10.1111/jnc.13580

Treasure, J., Cardi, V., \& Kan, C. (2012). Eating in eating disorders. Eur Eat Disord Rev, 20(1), e42-49. doi:10.1002/erv.1090

Turnbull, S., Ward, A., Treasure, J., Jick, H., \& Derby, L. (1996). The demand for eating disorder care. An epidemiological study using the general practice research database. Br J Psychiatry, 169(6), 705-712.

Turton, R., Bruidegom, K., Cardi, V., Hirsch, C. R., \& Treasure, J. (2016). Novel methods to help develop healthier eating habits for eating and weight disorders: A systematic review and meta-analysis. Neurosci Biobehav Rev, 61, 132-155. doi:10.1016/j.neubiorev.2015.12.008

Vall, E., \& Wade, T. D. (2015). Predictors of treatment outcome in individuals with eating disorders: A systematic review and meta-analysis. Int J Eat Disord. doi:10.1002/eat.22411

Volkow, N. D., \& Fowler, J. S. (2000). Addiction, a disease of compulsion and drive: involvement of the orbitofrontal cortex. Cerebral Cortex, 10(3), 318-325. 
Volkow, N. D., Fowler, J. S., Wang, G.-J., \& Swanson, J. M. (2004). Dopamine in drug abuse and addiction: results from imaging studies and treatment implications. Mol Psychiatry, 9(6), 557.

Voon, V., Derbyshire, K., Ruck, C., Irvine, M. A., Worbe, Y., Enander, J., . . B Bullmore, E. T. (2015). Disorders of compulsivity: a common bias towards learning habits. Mol Psychiatry, 20(3), 345-352. doi:10.1038/mp.2014.44

Voon, V., Morris, L. S., Irvine, M. A., Ruck, C., Worbe, Y., Derbyshire, K., . . Grant, J. E. (2015). Risk-taking in disorders of natural and drug rewards: neural correlates and effects of probability, valence, and magnitude. Neuropsychopharmacology, 40(4), 804-812. doi:10.1038/npp.2014.242

Wang, G.-J., Volkow, N. D., Thanos, P. K., \& Fowler, J. S. (2004). Similarity between obesity and drug addiction as assessed by neurofunctional imaging: a concept review. Journal of addictive diseases, 23(3), 39-53.

Wardle, J., Llewellyn, C., Sanderson, S., \& Plomin, R. (2009). The FTO gene and measured food intake in children. International Journal of Obesity, 33(1), 42-45.

Wilson, V. (2012). Reflections on reducing insulin to lose weigh. Nurs Times, 108(43), 2122,25 .

Wiss, D. A., \& Brewerton, T. D. (2016). Incorporating food addiction into disordered eating: the disordered eating food addiction nutrition guide (DEFANG). Eat Weight Disord. doi:10.1007/s40519-016-0344-y

Wiss, D. A., Criscitelli, K., Gold, M., \& Avena, N. (2017). Preclinical evidence for the addiction potential of highly palatable foods: Current developments related to maternal influence. Appetite, 115, 19-27. doi:10.1016/j.appet.2016.12.019 
Young, V., Eiser, C., Johnson, B., Brierley, S., Epton, T., Elliott, J., \& Heller, S. (2013). Eating problems in adolescents with Type 1 diabetes: a systematic review with metaanalysis. Diabet Med, 30(2), 189-198. doi:10.1111/j.1464-5491.2012.03771.x

Zeevi, D., Korem, T., Zmora, N., Israeli, D., Rothschild, D., Weinberger, A., . . LotanPompan, M. (2015). Personalized nutrition by prediction of glycemic responses. Cell, 163(5), 1079-1094. 